\title{
Effect of shoulder kinesiotaping versus low level laser in treatment of shoulder impingement syndrome
}

\author{
Noha Elserty* \\ PHD in physical therapy, physical therapist, physical therapy department, El sahel teaching hospital, Egypt
}

Received: April 17, 2017; Accepted: May 12, 2017; Published: May 24, 2017

*Corresponding author: Noha Elserty, PHD in physical therapy, physical therapist, physical therapy department, El sahel teaching hospital,Egypt, Tel: 0020-22049038; E-mail: noha_elserty@hotmail.com

\begin{abstract}
Objectives: This study aimed to investigate the effect of kinesiotaping versus low level laser in treatment of shoulder impingement syndrome.
\end{abstract}

Design: Randomized clinical trial.

Location: This study conducted at El Sahel teaching hospital, Egypt.

Subjects: Seventy five patients with shoulder impingement syndrome assigned into three equal groups. Their ages were ranged from 20 - 40 years.

Intervention: The three groups received the same exercise program and group (A) received kinesiotaping over supraspinatus muscle and deltoid muscle, tape removed every 3 days and patients return back for retaping. Group (B) received laser with $4 \mathrm{~J} / \mathrm{cm}^{2}$ for $90 \mathrm{sec}$ over the greater tuberosity of humerus and deltoid insertion. Group (C) received exercises only. Treatment sessions were applied 3 times / week for 4 weeks for the three groups.

Outcome measures: Visual analogue scale was used to assess pain severity, shoulder pain and disability index was used to assess functional ability level and electrogoniometer was used to assess shoulder flexion and abduction range of motion.

Results: Pain level was markedly decreased in the kinesiotaping group than low level laser group or control group. Also shoulder functional level and shoulder flexion and abduction range of motion were improved in kinesiotaping group than the other groups.

Conclusion: According to the results of this study adding kinesiotaping or low level laser to exercise program is effective in treatment of shoulder impingement syndrome. While kinesiotaping is more effective than low level laser and produce better improvement in pain level, functional activity and shoulder range of motion.

Keywords: Kinesiotaping; Low level laser; Shoulder impingement

\section{Introduction}

Shoulder impingement syndrome is a common musculoskeletal problem that can be defined as symptomatic compression of the sub acromial structures [1]. The patient's main complains is anterior-lateral shoulder pain when lifting the arm above shoulder level and during overhead activities [2]. There are many factors that leads to the development of shoulder impingement syndrome include inflammation of the tendons and bursa, degeneration of the tendons, postural dysfunctions and weak or dysfunctional rotator cuff and scapular musculature [3].

The recommended management of shoulder symptoms starts with educational information about the natural course of shoulder pain combined with the advise to avoid irritating and loading activities. The use of analgesics or NSAIDs is recommended for the first two weeks. When no recovery occurs within two weeks, sub acromial or intraarticular injection therapy with corticosteroids are administered and eventually repeated. Finally, physical therapy is only recommended after a 6-week period when there are functional limitations (specifically an activating and time-contingent approach) [4].

Many treatments for Shoulder Impingement Syndrome (SIS) are available in clinical practice; some of which have already been compared with other treatments by various investigators. However, a comprehensive treatment comparison is lacking. The evidence suggests that supervised and home-based progressive shoulder strengthening and stretching are effective for the management of sub acromial impingement syndrome [5].

Recently, kinesiotaping has become increasingly popular for a range of musculoskeletal conditions and for sport injuries [6].

Kinesiotaping is a technique which uses the application of an elastic adhesive tape on the skin. Kinesiotaping is manufactured with elastic cotton which can be stretched from 120 to $140 \%$ its original length. It is claimed that Kinesiotaping supports injured muscles and joints and helps to relieve pain by lifting the skin, thus improving blood and lymph flow [7].

Kinesiotaping is seemed to have effect in treatment of shoulder impingement as it might serves as an alternative treatment in case injection of corticosteroids are contraindicated [8]. 
Laser is a noninvasive, nonionizing, monochromatic electromagnetic high concentrated light beam. Recently, Low Level Laser Therapy (LLLT) is widely used in various rheumatologic and musculoskeletal disorders which have analgesic, anti-inflammatory and bio stimulating effects. The LLLT induces cell proliferation, collagen synthesis, protein synthesis, tissue reparation, wound healing and pain relief through direct irradiation without thermal response [9].

LLLT may be considered as an effective alternative to ultrasound based therapy in patients with sub acromial impingement syndrome especially ultrasound based therapy is contraindicated [10].

As shoulder impingement syndrome is a common problem; selection of effective modalities for treatment is very important that give rise to the question whether adding kinesiotaping or LLLT to exercise program will produce better results or not.

\section{Method}

Design: The design of the study was randomized control clinical trial, with pre-post measurements.

Participant: The current study was conducted at El Sahel teaching hospital at Cairo, patient were referred from the outpatient orthopedic clinic at El Sahel teaching hospital after being examined by the orthopedist, who was blinded about the treatment groups, to exclude patient with exclusion criteria (a copy of exclusion criteria were sent to orthopedic clinic). Based on power analysis, the sample size was 120 patients but not all the patient completes the study. Their ages were ranged from 25 to 40 years old. Subjects who participated in this study had at least 3 of the following inclusion criteria:

1.Positive Neer sign: The humerus was passively flexed to endrange with overpressure. Reproduction of pain confirms the presence of impingement syndrome.

2.Positive Hawkins sign: The shoulder was passively placed in approximately 90 degrees of flexion and is passively internally rotated to end-range with overpressure, reproducing patient's pain.

3.Pain with active shoulder elevation in the scapular plane.

4.Pain with palpation of the rotator cuff tendons.

5.Pain with resisted isometric shoulder abduction.

Subjects had been excluded when they had any of the following exclusion criteria

1.Current symptoms related to cervical spine.

2.Positive tests for shoulder instability:

a.Sulcus sign: A positive sulcus sign was an excessive downward movement of the humeral head away from the acromion when an inferior pull is placed on the humerus while the arm was in a dependent position.

\section{b.History of shoulder dislocation.}

3.Acromioclavicular pain: with the arm flexed to approximately
90 degrees, pain was reproduced by passively adducting and internally rotating the humerus across the chest to approximate the acromioclavicular joint.

4. Frozen shoulder as a complication of rotator cuff impingement syndrome.

5.Any other pathology of shoulder as degenerative arthritis.

6.A history of pain in the C5- C6 dermatome.

After selection through consultation with an orthopedist, the patients provided their written consent and were given an opportunity to ask any questions regarding the procedure. The study program had been approved by the ethical committee of general organization of teaching hospitals and institutes. Sealed envelope used for allocation of patient over the 3 groups by other clinician who was blinded about the study, then pre-treatment measurement were applied by the main researcher who was blinded about to which group patient was allocated.

\section{Intervention}

Study was performed in 9 months, treatment program given in 12 sessions ( 3 sessions per week) for the 3 groups. The patients were examined and data recorded in a pre-prepared card. Some patients (45 patients) didn't continue the full program of the study as their symptoms relieved without continuing the full program of the study and discontinuing their sessions by their own desire while75 patients continue the full program of the study.

Patients were divided into three equal groups (A,B, and $C)$. Group A: $(n=25)$ received kinesiotaping with exercise program, group $B$ : $(n=25)$ received LLLT with exercise program and group $C$ : $(n=25)$ received exercise program only.

Treatment had been carried out in physical therapy outpatient clinic of El- Sahel teaching hospital. The program of the study was given for three groups three sessions per week for four weeks. All groups had received the same exercises (which includes flexibility and strengthening program. The flexibility program was consisting of stretching exercise for the posterior and inferior shoulder capsule. The strengthening exercise was performed for shoulder flexors and abductors by carrying a proper weights and elastic bands.

Group A: patients received the exercise program plus kinesiotaping over supraspinatus muscle and deltoid muscle, tape was removed every three days and subjects returned back to the clinic to reapplication of tape again. Patients receive the same therapeutic exercise as the other 2 groups 3 times/ week.

Group B: patients received the exercise program plus laser with 4J $/ \mathrm{cm}^{2}$ for 90 sec over the common trigger points in impingement syndrome which were: over the greater tuberosity of humerus and deltoid insertion 3 times/ week.

\section{Outcome measures}

The measurements used in this study were Visual Analogue Scale (VAS), shoulder pain and disability index, and shoulder range of motion (flexion and abduction) measured 
by electrogoniometer. These measurement were selected to be applied in this study because it was thought that patient with shoulder impingement syndrome will suffer from pain that has an effect on functional level and range of motion, so assessment of pain, functional abilities and range of motion used to evaluate the efficacy of the study program.

Pain was assessed by using the visual analog scale, each subject was made aware the VAS as being $10 \mathrm{~cm}$ horizontal line with one end described as (no pain $=0$ ), and other end (the worst pain I ever felt $=10$ ). Patients were asked to mark a point on the line between the extremes that relates to their level of pain.

The shoulder pain and disability index is an acceptable tool to measure disability caused by shoulder impingement syndrome in the general population. Patients were instructed to mark at the point which refers to their degree of pain during ADL in the first subscale, and to their degree of difficulty in performing ADL in the other subscale.

Each item is scored by measuring their distance from the left anchor to the mark made by the patient. Subscales are scored in a 3 part process. First, item scores within subscale are summed. Second, the sum is divided by the summed distance possible across all items of the subscale to which the person respond. Third, this ratio is multiplied by 100 to obtain a percentage. To obtain the SPADI total score, the pain and disability subscales scores are averaged [11].

Active shoulder flexion and abduction were measured by the electrogoniometer device. Every measurement was performed 3 times and the average measurement was recorded.

For measuring flexion: The fulcrum of the electrogoniometer was fixed over the lateral border of the tip of acromion and the fixed arm stabilized parallel to lateral border of trunk, while the moveable arm stabilized on the lateral border of the humerus. The patient was instructed to move into full flexion as much as he can and at the end of movement the angle was recorded by the therapist.

For measuring abduction: The fulcrum of the electrogoniometer was fixed over the anterior border of the acromion process and the fixed arm stabilized parallel to the anterior border of trunk, while the moveable arm stabilized parallel to the anterior border of the humerus. The patient was instructed to move into full abduction as much as he can, and at the end of movement the angle was recorded by the therapist.

\section{Data analysis}

SPSS program was used to analyze the data. Statistics of this study was performed by a lecturer of biostatistics at statistics institute at Cairo University and he was asked about the patients groups. Test of normality for pre scores for the three groups was performed using SPSS program (Kolmogorov-Smirnov test and Shapiro-Wilk test) and revealed that the data is normally distributed. Descriptive statistics (mean and standard deviation) for VAS scores, shoulder pain and disability index scores and shoulder flexion and abduction range of motion for three groups were used. One way analysis of variance test was used to compare the variable among the three groups.

\section{Results}

\section{CONSORT flow chart of the paients was made}

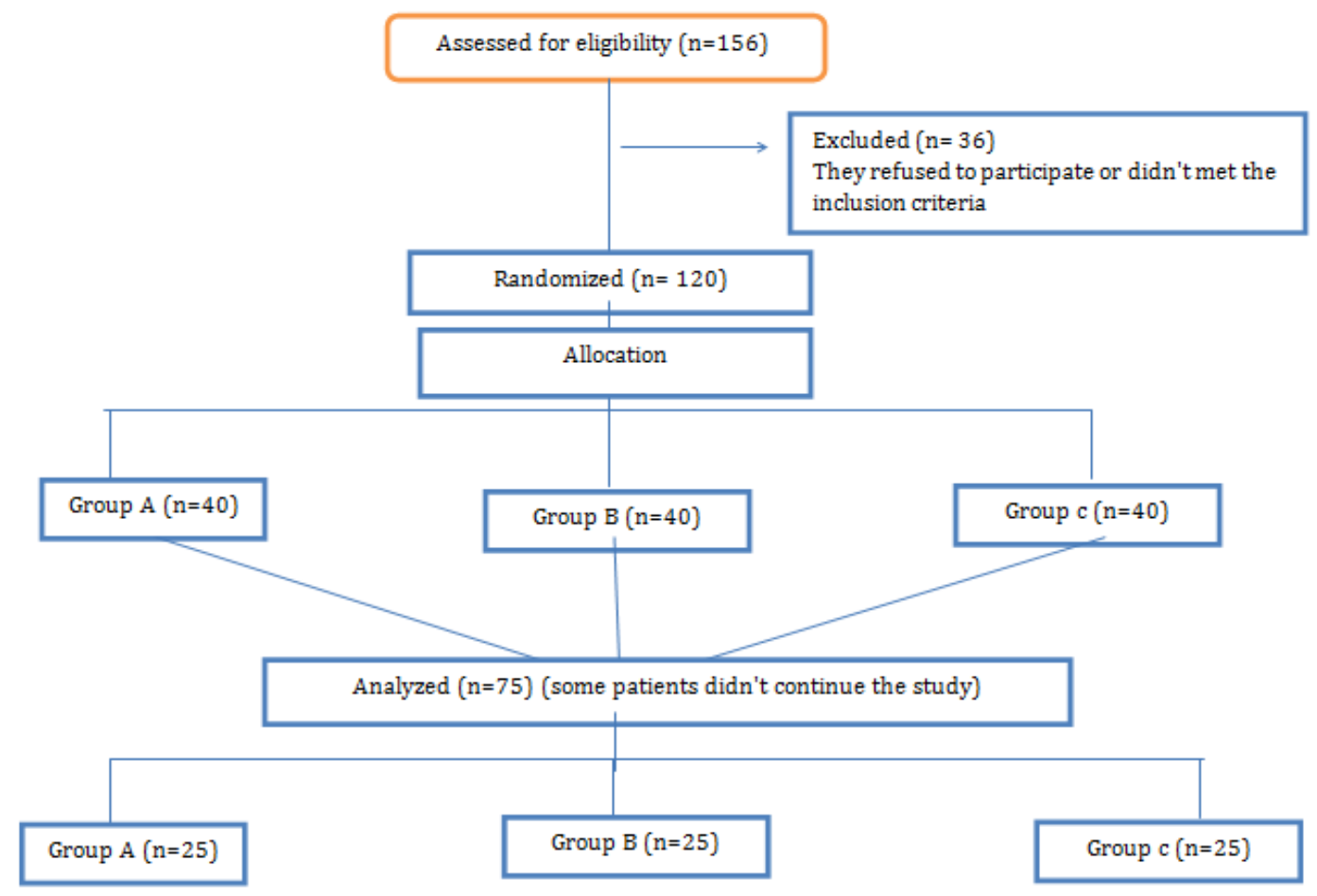


Seventy five patients 30 male (40\%) and 45 female $(60 \%)$ with shoulder impingement syndrome assigned into 3 equal groups. Group A: $(n=25)$ their mean age was $(32.6 \pm 2.79)$ years, group $B:(n=25)$ their mean age was $(34.8 \pm 7.22)$ years and group C: $(n=25)$ their mean age was $(34.6 \pm 6.75)$ years. Patients physical characteristics are represented in [Table 1].

\begin{tabular}{|l|c|c|c|}
\hline \multicolumn{1}{|c|}{ Table 1: Patient physical characteristics (descriptive statistics) } \\
\hline $\begin{array}{c}\text { Statistical } \\
\text { Values }\end{array}$ & Age (Years) & Weight (kg) & Height (cm) \\
\hline Mean & & & \\
Group A & 32.6 & 63.5 & 163.5 \\
Group B & 34.8 & 64.4 & 164.5 \\
Group C & 34.6 & 62.8 & 163.1 \\
\hline Standard & & & \\
error & $\pm \mathbf{2 . 7 9}$ & 8.03 & 4.71 \\
Group A & 7.22 & 6.46 & 3.95 \\
Group B & 6.75 & 7.03 & 3.63 \\
Group C & & & \\
\hline
\end{tabular}

Patient in the study didn't receive physical therapy sessions before, and most of them (75\% of the patients) suffer from shoulder impingement treated before by medications. Patient's jobs were varied; most of female patients were housewives while some male patients were workers. The results of ANOVA revealed no difference in all patients' measurements pretreatment while there is significant difference between groups in all patient measurements post treatment as shown in [Tables 2-5].

\begin{tabular}{|l|l|l|l|l|l|l|l|}
\hline \multicolumn{6}{|l|}{ Table 2: Results of ANOVA among the three groups for pain level } \\
\hline Pain level & SS & MS & F & $\begin{array}{l}\text { P } \\
\text { value }\end{array}$ & S \\
\hline Pre Treatment & $\begin{array}{l}\text { Between } \\
\text { Groups } \\
\text { Within } \\
\text { Groups } \\
\text { Total }\end{array}$ & $\begin{array}{l}0.26 \\
18.7\end{array}$ & 0.13 & 0.69 & 0.19 & $\mathbf{0 . 8 2}$ & NS \\
\hline Post Treatment & $\begin{array}{l}\text { Between } \\
\text { Groups } \\
\text { Within } \\
\text { Groups } \\
\text { Total }\end{array}$ & $\begin{array}{l}20.06 \\
27.4\end{array}$ & 10.03 & 1.01 & 9.88 & $\mathbf{0 . 0 0 1}$ & $\mathrm{S}$ \\
\hline
\end{tabular}

NS: No significant. S: Significant

\begin{tabular}{|c|c|c|c|c|c|c|}
\hline \multicolumn{2}{|c|}{$\begin{array}{l}\text { Functional disability level } \\
\text { SPADI }\end{array}$} & \multirow{2}{*}{$\begin{array}{l}\text { SS } \\
218.17 \\
1079.7 \\
1297.88\end{array}$} & \multirow{2}{*}{$\begin{array}{l}\text { MS } \\
109.08 \\
39.98\end{array}$} & \multirow{2}{*}{$\begin{array}{l}\mathbf{F} \\
2.72\end{array}$} & \multirow{2}{*}{$\begin{array}{l}\mathbf{P} \\
\text { value } \\
0.08\end{array}$} & \multirow{2}{*}{\begin{tabular}{|l|l}
$\mathbf{s}$ \\
\\
NS
\end{tabular}} \\
\hline Pre Treatment & $\begin{array}{l}\text { Between } \\
\text { Groups } \\
\text { Within } \\
\text { Groups } \\
\text { Total }\end{array}$ & & & & & \\
\hline Post Treatment & $\begin{array}{l}\text { Between } \\
\text { Groups } \\
\text { Within } \\
\text { Groups } \\
\text { Total }\end{array}$ & $\begin{array}{l}3542.2 \\
1256.64 \\
4798.84\end{array}$ & $\begin{array}{l}1771.1 \\
46.54\end{array}$ & 38.05 & 0.0001 & $S$ \\
\hline
\end{tabular}

SPADI: shoulder pain and disability index. NS: No significant. S: Significant
Table 4: Results of ANOVA among the three groups pretreatment for shoulder flexion

\begin{tabular}{|c|c|c|c|c|c|c|}
\hline \multicolumn{2}{|r|}{ Shoulder flexion } & SS & MS & $\mathbf{F}$ & $P$ value & $\mathbf{S}$ \\
\hline $\begin{array}{l}\text { Pre } \\
\text { Treatment }\end{array}$ & $\begin{array}{l}\text { Between } \\
\text { Groups } \\
\text { Within Groups } \\
\text { Total }\end{array}$ & $\begin{array}{l}220.86 \\
3255.3 \\
3476.16\end{array}$ & $\begin{array}{l}110.43 \\
120.56\end{array}$ & 0.91 & 0.41 & NS \\
\hline $\begin{array}{l}\text { Post } \\
\text { Treatment }\end{array}$ & $\begin{array}{l}\text { Between } \\
\text { Groups } \\
\text { Within Groups } \\
\text { Total }\end{array}$ & $\begin{array}{l}2890.86 \\
3874.1 \\
6764.96\end{array}$ & $\begin{array}{l}1445.43 \\
143.48\end{array}$ & 10.07 & 0.001 & S \\
\hline
\end{tabular}

Table 5: Results of ANOVA among the three groups for shoulder abduction

\begin{tabular}{|c|c|c|c|c|c|c|}
\hline \multicolumn{2}{|c|}{ Shoulder abduction } & SS & MS & $\mathbf{F}$ & $P$ value & $\mathbf{S}$ \\
\hline $\begin{array}{l}\text { Pre } \\
\text { Treatment }\end{array}$ & $\begin{array}{l}\text { Between } \\
\text { Groups } \\
\text { Within } \\
\text { Groups } \\
\quad \text { Total }\end{array}$ & $\begin{array}{l}154.46 \\
3049.4 \\
3203.86\end{array}$ & $\begin{array}{l}77.23 \\
112.94\end{array}$ & 0.68 & 0.51 & NS \\
\hline $\begin{array}{l}\text { Post } \\
\text { Treatment }\end{array}$ & $\begin{array}{l}\text { Between } \\
\text { Groups } \\
\text { Within } \\
\text { Groups } \\
\quad \text { Total }\end{array}$ & $\begin{array}{l}3678.86 \\
3058.6 \\
6737.46\end{array}$ & $\begin{array}{l}1839.43 \\
113.28\end{array}$ & 16.23 & 0.0001 & S \\
\hline
\end{tabular}

NS: No significant. S: Significant

Post hoc test was used to determine the difference among groups in post treatment. For pain level and shoulder flexion ROM there was a significant difference in level of improvement between groups A and B and there was a highly significant difference in level of improvement between groups $\mathrm{A}$ and $\mathrm{C}$ while there was no significant difference in level of improvement between groups $\mathrm{B}$ and $\mathrm{C}$ as shown in [Table 6,7]

Table 6: Post hoc test among the three groups for pain level

\begin{tabular}{|l|l|l|l|l|}
\hline \multicolumn{2}{|c|}{ Pain level } & $\begin{array}{l}\text { Mean } \\
\text { difference }\end{array}$ & P value & S \\
\hline \multirow{2}{*}{ Post Treatment } & Group A vs group B & 1.1 & 0.02 & S \\
\cline { 2 - 5 } & Group A vs. group C & 2.0 & 0.0001 & S \\
\cline { 2 - 5 } & Group B vs. group C & 0.9 & 0.056 & NS \\
\hline
\end{tabular}

NS: No significant. S: Significant

Table 7: Post hoc test among the three groups for shoulder flexion

\begin{tabular}{|l|l|l|l|l|}
\hline \multicolumn{2}{|c|}{ Shoulder flexion } & $\begin{array}{l}\text { Mean } \\
\text { difference }\end{array}$ & P value & S \\
\hline \multirow{2}{*}{ Post Treatment } & Group A vs. group B & 17.8 & 0.003 & S \\
\cline { 2 - 5 } & Group A vs. group C & 22.9 & 0.0001 & S \\
\cline { 2 - 5 } & Group B vs. group C & 5.1 & 0.35 & NS \\
\hline
\end{tabular}

NS: No significant. S: Significant 
Concerning functional level there was a highly significant difference in level of improvement between groups $\mathrm{A}$ and $B \& A$ and $C \& B$ and $C$ as shown in [Table 8].

For shoulder abduction ROM there was a significant difference in level of improvement between groups A and B, and there was a significant difference in level of improvement between groups A and C. While there was no significant difference in level of improvement between groups B and C as shown in [Table 9].

Table 8: Post hoc test among the three groups for SPADI

\begin{tabular}{|l|l|l|l|l|}
\multicolumn{2}{|c|}{ Functional disability level } & $\begin{array}{l}\text { Mean } \\
\text { SPADI }\end{array}$ & P value & S \\
\hline \multirow{2}{*}{ Post Treatment } & Group A vs. group B & 13.06 & 0.0001 & S \\
\cline { 2 - 5 } & Group A vs. group C & 26.61 & 0.00001 & S \\
\cline { 2 - 5 } & Group B vs. group C & 13.55 & 0.0001 & S \\
\hline
\end{tabular}

SPADI: shoulder pain and disability index. S: Significant

Table 9: Post hoc test among the three groups for shoulder abduction

\begin{tabular}{l|l|l|l|l|}
\multicolumn{2}{|c|}{ Shoulder abduction } & $\begin{array}{l}\text { Mean } \\
\text { difference }\end{array}$ & P value & S \\
\hline \multirow{2}{*}{$\begin{array}{l}\text { Post } \\
\text { Treatment }\end{array}$} & Group A vs. group B & 17.9 & 0.001 & S \\
\cline { 2 - 5 } & Group A vs. group C & 26.6 & 0.0001 & S \\
\cline { 2 - 5 } & Group B vs. group C & 8.7 & 0.07 & NS \\
\hline
\end{tabular}

NS: No significant. S: Significant

\section{Discussion}

Impingement syndrome is considered one of the most common shoulder disorders, accounting for $44-65 \%$ of all complaints of shoulder pain [12]. Conservative treatment is the first choice for most patients suffering from shoulder impingement, and the majority of these patients will recover with appropriate non-operative treatments [13].

It was concluded that strengthening of the rotator cuff muscles and scapular stabilizing muscles and stretching the soft tissues of the anterior and posterior shoulder were the options most supported physical therapy program [14]. In this study exercise program this exercise program was used in adjunction with two modalities (kinesiotaping and low level laser) that commonly used to treat pain to gain better results of physical therapy program.

In this study pain level was markedly decreased in the kinesiotaping group than low level laser group or control group. Also shoulder functional level and shoulder flexion and abduction range of motion were improved in kinesiotaping group than the other groups.

There are many studies support the use of kinesiotaping in different musculoskeletal problems and support its use as a prophylactic technique especially in sports medicine. It was suggested that kinesiotaping causes positive changes in scapular motion. This could support its use in sports medicine for preventing shoulder problems [15].
The effect of Kinesiotaping in shoulder impingement may be due to its effect on acomiohumeral distance as it was found that kinesiotaping increases acromiohumeral distance in healthy individuals immediately following application, compared with sham kinesiotape [16]. Also it has positive effect on shoulder rotator strength and range of motion. Therefore, scapular taping could be recommended for not only in the asymptomatic athletes' shoulder exercise training but also in the prevention of sub acromial impingement syndrome [17].

Kinesiotape creates pressure on the skin and stretches the skin. By stimulating cutaneous mechanoreceptors, this external loading causes physiological changes in the region where KT was applied. KT increases the distance between skin and muscle and interstitial fluid by increasing the blood and lymphatic circulation [18].

Low level laser was used in treatment of different musculoskeletal problems. The effectiveness of low-level laser treatment was similar to that of local corticosteroid injection in patients with sub acromial impingement syndrome [19].

The bio modulatory effect of LLLT improves local microcirculation and oxygen supply to hypoxic cells in the painful areas. Simultaneously, tissue asphyxia is reduced to a minimum and collected waste products are removed. The laser-induced normalization of microcirculation interrupts the vicious cycle that originates, develops, and maintains pain; in addition, it restores the normal physiological condition of the tissue [20].

Research has shown that LLLT can modulate inflammation by reducing the levels of biochemical markers (prostaglandin E2, messenger ribonucleic acid cyclooxygenase-2, interleukine$1 \beta$, and tumor necrotizing factor- $\alpha$ ), neutrophil influx, oxidative stress, edema, and hemorrhage in a dose-dependent manner [21].

\section{Conclusion}

According to the results of this study adding kinesiotaping or low level laser to exercise program is effective in treatment of shoulder impingement syndrome. While kinesiotaping is more effective than low level laser and produce better improvement in pain level, functional activity and shoulder range of motion.

\section{References}

1. Bigliani LU, Levine WN. Current concepts review. Subacromial impingement syndrome. J Bone Joint Surg. 1997;79:1854-1868.

2. Haldorsen B, Svege I, Roe Y, Bergland A. Reliability and validity of the Norwegian version of the Disabilities of the Arm, Shoulder and Hand questionnaire in patients with shoulder impingement syndrome.BMC Musculoskelet Disord. 2014;15:78.

3. Michener LA, McClure PW, Karduna AR. Anatomical and biomechanical mechanisms of subacromial impingement syndrome. ClinBiomech (Bristol, Avon). 2003;18:369-379.

4. CarelBron, Michel Wensing, Jo LM Franssen, Rob AB Oostendorp. Treatment of myofascial trigger points in common shoulder disorders by physical therapy: A randomized controlled trial. BMC Musculoskelet Disord. 2007; 8: 107.

5. Abdulla SY, Southerst D, Côté P, Shearer HM, Sutton D, Randhawa K, et al. Is exercise effective for the management of subacromial impinge- 
ment syndrome and other soft tissue injuries of the shoulder? A systematic review by the Ontario Protocol for Traffic Injury Management (OPTIMa) Collaboration. Man Ther. 2015;20(5):646-656.

6. Luque-Suarez A, Navarro-Ledesma S, Petocz P, Hancock MJ, Hush J. Short term effects of kinesiotaping on acromiohumeral distance in asymptomatic subjects: a randomised controlled trial. Man Ther. 2013;18(6):573-577.

7. Kase K, Wallis J, Kase T. Clinical therapeutic applications of the kinesio taping method. Ken Ikai Company Limited. 2003;25-32.

8. ŞahinOnat Ş, Biçer S, Şahin Z, Küçükali Türkyilmaz A, Kara M, Özbudak Demir S. Effectiveness of Kinesiotaping and Subacromial Corticosteroid Injection in Shoulder Impingement Syndrome. Am J Phys Med Rehabil. 2016;95(8):553-560.

9. Sebnem Koldas Dogan, Saime AY, Deniz Evcik. The effectiveness of low laser therapy in subacromial impingement syndrome: a randomized placebo controlled double-blind prospective study. Clinics (Sao Paulo). 2010 ;65(10):1019-1022.

10. Yavuz F, Duman I, Taskaynatan MA, Tan AK. Low-level laser therapy versus ultrasound therapy in the treatment of subacromialimpingement syndrome: a randomized clinical trial. J Back Musculoskelet Rehabil. 2014;27(3):315-320.

11. Roddy T, Olson S, Cook K, Gartsman GM, Hanten W. Comparison of the University of California-Los Angeles Shoulder Scale and the Simple Shoulder Test with the Shoulder Pain and Disability Index: SingleAdministration Reliability and Validity. PHYS THER. 2000;80(8):759768.

12. Mattiello-Rosa SM, Camargo PR, Santos AA, Pádua M, et al. Abnormal isokinetic time-to-peak torque of the medial rotators of the shoulder in subjects with impingement syndrome. J Shoulder Elbow Surg. 2008;17:S54-S60
13. Henrichs J, Stone D. Shoulder impingement syndrome. Prim Care. 2004;31:789-805.

14. Michener LA, Walsworth MK, Burnet EN. Effectiveness of rehabilitation for patients with subacromial impingement syndrome: a systematic review. J Hand Ther. 2004;17:152-164.

15. Van Herzeele M, van Cingel R, Maenhout A, De Mey K, Cools A. Does the application of kinesiotape change scapular kinematics in healthy female handball players? Int J Sports Med. 2013;34(11):950-955.

16. Luque-Suarez A, Navarro-Ledesma S, Petocz P, Hancock MJ, Hush J. Short term effects of kinesiotaping on acromiohumeral distance in asymptomatic subjects: a randomised controlled trial. Man Ther. 2013;18(6):573-577.

17. Harput G, Guney H, Toprak U, Colakoglu F, Baltaci G. Acute effects of scapular kinesiotaping on shoulder rotator strength, range of motion and acromiohumeral distance in asymptomatic overhead athletes. J Sports Med Phys Fitness. 2016;8.

18. Yoshida A, Kahanov L. The effect of kinesio taping on lower trunk range of motions. Res Sports Med. 2007;15:103-112.

19. Kelle B, Kozanoglu E. Low-level laser and local corticosteroid injection in the treatment of subacromial impingement syndrome: a controlled clinical trial. Clin Rehabil. 2014;28(8):762-771.

20. Bjordal JM, Johnson MI, Iversen V, Aimbire F, Lopes-Martins RA. Photoradiation in acute pain: a systematic review of possible mechanisms of action and clinical effects in randomized placebo-controlled trials. Photomed Laser Surg.2006;24:158-68.

21. Peres e Serra A, Ashmawi HA. Influence of naloxone and methysergide on the analgesic effects of low-level laser in an experimental pain model. Rev Bras Anestesiol. 2010;60:302-310. 